\title{
Novel Therapeutic Approaches for Epstein-Barr Virus Associated Gastric Cancer
}

\author{
BYUNG WOOG KANG ${ }^{1}$, DONG WON BAEK ${ }^{1}$, HYOJEUNG KANG $^{2}$, JIN HO BAEK ${ }^{1}$ and JONG GWANG KIM ${ }^{1}$ \\ ${ }^{1}$ Department of Oncology/Hematology, Kyungpook National University Chilgok Hospital, School of Medicine, \\ Kyungpook National University, Kyungpook National University Cancer Research Institute, Daegu, Republic of Korea; \\ ${ }^{2}$ College of Pharmacy, Kyungpook National University, Daegu, Republic of Korea
}

\begin{abstract}
Epstein-Barr virus (EBV)-associated gastric cancer $(G C)$ (EBVaGC) is classified as one of four GC subtypes by comprehensive molecular characterization. Though the mechanism of tumorigenesis by EBV infection has not yet been fully clarified, EBV infection might contribute to the malignant transformation of GC cells by involving various cellular processes and signaling pathways. EBVaGC has shown the following distinct characteristics in contrast to other subtypes: extreme DNA hypermethylation, recurrent phosphatidylinositol 4,5-biphosphate 3-kinase catalytic subunit alpha isoform (PIK3CA) mutations, overexpression of programmed cell death ligand 1/2 (PDL1/2), and occasional immune cell signaling activation. Therefore, using these molecular features as guides, targeted agents need to be evaluated in clinical trials for EBVaGC. Accordingly, this review uses the best available evidence to focus on novel therapeutic approaches using the distinct pathologic characteristics of EBVaGC patients.
\end{abstract}

Advanced gastric cancer (AGC) remains a major public health problem and the second leading cause of cancerrelated deaths worldwide, even though rapid advances in treatment options have improved its prognosis $(1,2)$.

Correspondence to: Jong Gwang Kim, MD, Ph.D., Department of Oncology/Hematology, Kyungpook National University Chilgok Hospital, School of Medicine, Kyungpook National University, Kyungpook National University Cancer Research Institute, Daegu, Republic of Korea. Tel: +82 532002623, Fax: +82 532002027, e-mail: jkk21c@knu.ac.kr; Jin Ho Baek, MD, Ph.D., Department of Oncology/Hematology, Kyungpook National University Chilgok Hospital, School of Medicine, Kyungpook National University, Kyungpook National University Cancer Research Institute, Daegu, Republic of Korea. Tel: +82 532002623, Fax: +82 532002027, e-mail:wwhite71@hanmail.net

Key Words: Epstein-Barr virus, gastric cancer, treatment, review.
Recently, remarkable progress in tumour biology has led to the development of new therapeutics that target critical aspects of oncogenic pathways or the immune system. In case of AGC, various target agents have already been evaluated in randomized studies, where trastuzumab (antihuman epidermal growth factor receptor 2 (HER2) monoclonal antibody) exhibited anti-tumor activity against 15-20\% of HER2-positive AGC (3), while ramucirumab (anti-vascular endothelial growth factor receptor 2 (VEGFR2) monoclonal antibody) and nivolumab (antiprogrammed cell death protein 1 (PD-1) monoclonal antibody) were shown to improve survival duration in a second or third-line setting $(4,5)$. However, most responses to chemotherapy with targeted agents are limited and short in duration, with a median survival of 10 16 months and overall survival at 2 years rarely over $10 \%$ (6).

Epstein-Barr virus (EBV)-associated gastric cancer (GC) (EBVaGC) is classified as one of four GC subtypes by the comprehensive molecular characterization (tumors positive for EBV, microsatellite unstable tumors, genomically stable tumors, tumors with chromosomal instability) (7). Though the mechanism of tumorigenesis by EBV infection has not yet been fully clarified, EBV infection might contribute to malignant transformation of GC cells by involving various cellular processes and signaling pathways (8). EBVaGC has shown the following distinct characteristics when compared to other subtypes: extreme DNA hypermethylation, recurrent phosphatidylinositol 4,5-biphosphate 3-kinase (PI3K) catalytic subunit alpha isoform (PIK3CA) mutations, overexpression of programmed cell death ligand 1/2 (PDL1/2), and occasional immune cell signaling activation (7). Importantly, these molecular features can provide a guide for targeted agents that can be evaluated in clinical trials for EBVaGC. Accordingly, this review focuses on novel therapeutic approaches using the distinct pathological characteristics in patients with EBVaGC on the basis of the best available evidence. 


\section{Immuno-oncologic Treatment: Immune Checkpoint Inhibitor}

The recent identification of certain targets by The Cancer Genome Atlas (TCGA) Network has improved the accuracy when investigating the application of novel therapies to the four molecular subtypes of GC (7). EBV-positive tumours exhibit $C D K N 2 A$ promoter hypermethylation and recurrent PIK3CA mutations. These tumours also display PD-L1/2 overexpression frequently, and occasional immune cell signaling activation $(8,9)$. In particular, a subgroup of GC with EBV-positivity is characterized by heavy infiltration of lymphoid elements and is associated with inflammatory stroma and rich cytokine milieu (10). In addition, in previous studies of 120 patients with EBV-positive cancer, the current authors showed that high levels of tumor-infiltrating lymphocytes associate with a favorable prognosis and intratumoral PD-L1 positivity with a worse prognosis (11, 12). Therefore, such findings support the concept that immune checkpoint inhibitors can be used as cancer immunotherapy in GC patients with EBV and indicate a pivotal role of immune mechanisms in this GC subset.

To date, most clinical trials on immune checkpoint inhibitors have included GC patients regardless of the subtype. When tested as a treatment option for metastatic or recurrent GC, these inhibitors have been found to be promising drugs in combination or as single agents (Table I) (13). Pembrolizumab and nivolumab are the first two monoclonal antibodies targeting PD-1, thereby interfering with the interaction between PD-1 and PD-L1. Based on the results of the KEYNOTE-059 trial, pembrolizumab monotherapy demonstrated encouraging antitumor activity with acceptable safety in patients previously treated for advanced gastric and gastroesophageal junction cancer (14). The objective response rate and median response duration (range) were reported as $15.5 \%$ and 16.3 (1.6 to 17.3) months, respectively, in patients with PD-L1-positive tumors (15). Nivolumab was also clinically explored following the failure of standard management. The ONO-453812/ATTRACTION-2 trial compared nivolumab to the placebo in patients with unresectable or recurrent GC, which was refractory to or intolerant of at least two previous standard chemotherapy regimens (5). The results showed a significantly prolonged overall survival (OS) for the nivolumab group with a median OS of 5.26 months $(95 \% \mathrm{CI}=4.60-6.37)$ compared to 4.14 months (3.42-4.86) for the placebo (hazard ratio (HR) $0.63,95 \% \mathrm{CI}=0.51-0.78 ; p<0.0001)$. Although another trial (JAVELIN Gastric 300) did not achieve its primary end point of improving OS, avelumab, which is an anti-PD-L1 blocking monoclonal antibody, was still found to exhibit antitumor activity similar to chemotherapy in patients treated with two previous regimens for advanced cancer, and with more favorable safety profiles (16). Notwithstanding, most GC patients only respond temporarily to immune checkpoint inhibitors and then experience disease progression. Moreover, identification of more robust predictive biomarkers for immune checkpoint inhibitors is critical to optimize treatment with these agents (17).

As described above, EBV-positive tumors exhibit genomic amplification of genes encoding PD-L1 that may be potential biomarkers for immune checkpoint inhibitors (18). Interestingly, a recent phase II trial by Kim et al. showed a durable survival benefit associated with pembrolizumab in patients with EBV-positive tumors (19). This trial enrolled 61 patients with recurrent or metastatic GC (all sub-types). Twenty-nine patients received pembrolizumab as a third-line treatment, while 32 received pembrolizumab as a second-line therapy for metastatic disease. In a subgroup analysis, pembrolizumab showed a dramatic efficacy for patients with EBV-positive tumors (overall response rate (ORR), 100\%). In addition, the ORR was significantly superior for PD-L1positive GC compared to PD-L1-negative tumors (50.0\% versus $0.0 \% ; p<0.001)$. Therefore, these findings suggest that EBV-positive GC derives benefit from PD-L1 inhibition and can also be actively considered for up-front pembrolizumab monotherapy.

Meanwhile, accumulating evidence shows that PD-L1 expression could be a potential prognostic and predictive factor for immune checkpoint inhibitors. Therefore, understanding the implications of PD-L1 expression in patients with EBV infection is of critical importance. According to the recent meta-analysis of $1901 \mathrm{GC}$ patients, expression of PD-L1 was identified as a useful predictor of poor OS with final HR for OS of 1.64 (20). However, the evaluation of PD-L1 expression in patients with EBV is still insufficient. Notably, our research group demonstrated that PD-L1-positive EBVaGC patients exhibited a poorer prognosis than PD-L1-negative patients (12). Still, investigating PD-L1 expression has certain limitations that need to be considered (21). The evaluation and interpretation of PD-L1 within tumors and tumor microenvironment have not yet been standardized in GC. A standardized cut-off value for PD-L1 positivity has not yet been clearly established. Plus, conflicting results could also be due to different patient ethnicities and different antibody clones. Therefore, continuous research is needed to recognize additional predictive factors to identify the subgroup of EBV patients who can benefit from immunotherapy.

\section{Molecular Targeted Agents: Phosphoinositide 3-kinase Inhibitors}

GC molecular profiling has enabled the TCGA Research Network and Asian Cancer Research Group (ACRG) to classify GC into subtypes (22). For example, EBV-positive tumors have been found to represent $9 \%$ of TCGA GC samples with a strong predilection for PIK3CA mutation (80\%) (7). The 
Table I. Immune checkpoint inhibitors in EBVaGC.

\begin{tabular}{|c|c|c|c|c|c|c|c|c|}
\hline References & Indication & $\begin{array}{l}\text { Study } \\
\text { name }\end{array}$ & Agents & Target & Number & $\begin{array}{l}\text { Response } \\
\text { rate }(\%)\end{array}$ & $\begin{array}{c}\text { Overall } \\
\text { survival } \\
\text { (Months) }\end{array}$ & $\begin{array}{c}\text { Hazard ratio } \\
\& p \text {-value }\end{array}$ \\
\hline (14) & $\begin{array}{l}\text { Third-line or } \\
\text { later treatment }\end{array}$ & $\begin{array}{c}\text { KEYNOTE-059, } \\
\text { Phase II }\end{array}$ & $\begin{array}{c}\text { Pembrolizumab } 200 \mathrm{mg} \\
\text { every } 3 \text { weeks }\end{array}$ & PD-1 & 259 & $11.6(15.5)^{\dagger}$ & 5.6 & - \\
\hline (5) & $\begin{array}{l}\text { Second-line or } \\
\text { later treatment }\end{array}$ & $\begin{array}{l}\text { ONO-4538-12/ } \\
\text { ATTRACTION-2, } \\
\text { Phase III }\end{array}$ & $\begin{array}{c}\text { Nivolumab } \\
3 \mathrm{mg} / \mathrm{kg} \\
\text { every } 2 \text { weeks } \\
\text { Placebo }\end{array}$ & PD-1 & 163 & 11 & 5.26 & $\begin{array}{c}0.63 \\
(0.51-0.78) \\
p<0.0001\end{array}$ \\
\hline (16) & $\begin{array}{l}\text { Second-line or } \\
\text { later treatment* }\end{array}$ & $\begin{array}{l}\text { JAVELIN } \\
\text { Gastric 300, } \\
\text { Phase III }\end{array}$ & $\begin{array}{c}\text { Avelumab } \\
10 \mathrm{mg} / \mathrm{kg} \\
\text { every } 2 \text { weeks } \\
\text { Physician's choice } \\
\text { (paclitaxel or irinotecan) }\end{array}$ & PD-L1 & 185 & 2.2 & 4.6 & $\begin{array}{c}1.1(0.9-1.4) \\
p=0.81\end{array}$ \\
\hline (19) & $\begin{array}{l}\text { Second- or } \\
\text { third-line }\end{array}$ & Phase II & $\begin{array}{c}\text { Pembrolizumab } \\
200 \text { mg every } 3 \text { weeks }\end{array}$ & PD-1 & $61(6)^{* *}$ & $24.6(100)^{* *}$ & $(9.6)^{* * *}$ & - \\
\hline
\end{tabular}

$\dagger$ Response rate in patients with PD-L1-positive; †Includes treatments received in the adjuvant setting; *Includes patients who progressed on neoor adjuvant therapy within 6 months of treatment discontinuation; **patients with EBV-positive; ***median duration of response.

ACRG also found a $6.5 \%$ overall occurrence of EBV infection in GC patients and higher occurrence in the microsatellite stable with active tumor protein 53 (MSS/TP53+) subgroup. In particular, the MSS/TP53+ subtype showed a relatively higher prevalence of PIK3CA mutations (23). Therefore, these findings suggest that PIK3CA participates in several important cellular pathways that potentially play a role in tumorigenesis, warranting further investigation of PI3K inhibition in the case of EBVaGC (Table II).

PI3Ks are involved in various vital functions of cells, such as survival, proliferation, and differentiation (24). Divided into three main classes according to their functions, class I PI3Ks are mainly related with human cancers. Class I PI3Ks are heterodimers and composed of a p85 regulatory subunit and p110 catalytic subunit, where PIK3CA is part of the catalytic subunit (25). PIK3CA encodes the p110 catalytic subunit and can be up-regulated by activating molecular alterations (26). Essentially, PIK3CA mutations are frequently found in exon 1 , exon 4 , exon 5 , exon 9 , and exon 20. Among them, the mutations E545K and E542K in exon 9, and H1047R in exon 20 occur frequently in human cancers, while these mutations are more dispersed in EBVpositive tumors $(7,27)$. When alterations of class I PI3Ks occur, the p85 regulatory subunit loses its ability to inhibit overproduction and excessive release of phosphatidylinositol 3,4,5-triphosphate (PIP3), thereby promoting cell division through an increased release of protein kinase B (AKT) (2830). Interestingly, AKT overexpression has also been observed in multiple human cancers, including gastric adenocarcinomas (31). Moreover, previous studies have demonstrated that the PI3K/AKT/mammalian target of the rapamycin (mTOR) signaling pathway is frequently altered as a result of PIK3CA amplification or overexpression, which has already been shown to play a key role in the initiation and progress of malignant tumors $(32,33)$.

Although recurrent $P I K 3 C A$ mutations are considered a key parameter in EBV-positive tumors, their clinical significance in GC remains controversial. A recent genomic profiling study reported that activation of the $\mathrm{PI} 3 \mathrm{~K} / \mathrm{AKT} / \mathrm{mTOR}$ signaling pathway had a negative effect on OS and progression-free survival (PFS) in AGC (34). In contrast, Fang et al. demonstrated that PIK3CA amplification had no impact on either survival or the recurrence of GC (35). Another study by Ito et al. also found no correlation between PIK3CA mutations and prognosis for GC patients (36). Yet, very few studies have reported on the prognostic effects of $P I K 3 C A$ in EBVaGC, warranting further evaluation to determine the clinical implications of PIK3CA mutations.

A number of inhibitors to decrease the effect of the $\mathrm{PI} 3 \mathrm{~K} / \mathrm{AKT} / \mathrm{mTOR}$ pathway are currently under investigation. When evaluated as a second-line therapy in GC, the AKT inhibitor MK2206 failed to show sufficient impact on survival outcomes (37). Meanwhile, AZD5363 (NCT02451956) and GDC0068 (NCT01896531), also AKT inhibitors, are being evaluated in combination with conventional chemotherapeutic agents $(38,39)$. Everolimus, an mTOR inhibitor that is an oral formula of a rapamycin analogue, has been investigated in the phase III GRANITE-1 study (NCT00879333) in AGC patients who had progressed after one or two lines of systemic chemotherapy. Although everolimus did improve median PFS, there was no OS benefit (40). Various pan-class I PI3K inhibitors have also been reported, and recent clinical trials 
Table II. List of studies for PI3K and PIK3CA discussed in this review.

\begin{tabular}{|c|c|c|c|}
\hline Reference & $\begin{array}{l}\text { First author and } \\
\text { year of publication }\end{array}$ & Study design & Summary of findings \\
\hline (7) & $\begin{array}{l}\text { Cancer Genome Atlas } \\
\text { Research Network, } 2014\end{array}$ & $\begin{array}{l}\text { Experimental } \\
\text { research }\end{array}$ & $\begin{array}{l}\text { The EBV-positive tumors exhibited higher prevalence of } \\
\text { PIK3CA mutation ( } 80 \%) \text { which suggests that inhibition of } \\
\text { PIK3CA warrants further evaluation in EBV-positive GC. }\end{array}$ \\
\hline (35) & Diaz-Serrano et al., 2018 & $\begin{array}{l}\text { Experimental } \\
\text { research }\end{array}$ & $\begin{array}{c}\text { PI3K/AKT/mTOR signaling pathway activation could have } \\
\text { a differentially negative effect on OS and PFS in AGC. }\end{array}$ \\
\hline (41) & Ohtsu et al., 2013 & Phase III study & $\begin{array}{l}\text { Everolimus did not significantly improve overall survival for } \\
\text { advanced gastric cancer that progressed after one or two lines of } \\
\text { previous systemic chemotherapy, while the safety profile } \\
\text { observed for everolimus was consistent with that } \\
\text { observed for everolimus in other cancers. }\end{array}$ \\
\hline$(42)$ & Hong et al., 2012 & Phase I study & $\begin{array}{l}\text { PX-866, an irreversible small-molecule inhibitor of PI3K } \\
\text { was well tolerated and was associated with prolonged stable } \\
\text { disease, particularly when using a continuous dosing schedule. }\end{array}$ \\
\hline
\end{tabular}

Table III. Demethylating agents in EBVaGC.

\begin{tabular}{|c|c|c|c|}
\hline References & $\begin{array}{l}\text { First author and year } \\
\text { of publication }\end{array}$ & Study design & Summary of findings \\
\hline (60) & Jung et al., 2007 & $\begin{array}{l}\text { Experimental } \\
\text { research }\end{array}$ & $\begin{array}{l}\text { Low concentrations of demethylating agents, 5-azacitidine or } \\
\text { trichostatin A, induced the expression of EBV lytic genes, } \\
\text { such as BMRF1, BZLF1, and BRLF1 in EBVaGC cell line. }\end{array}$ \\
\hline (63) & Nakamura et al., 2017 & $\begin{array}{l}\text { Experimental } \\
\text { research }\end{array}$ & $\begin{array}{l}\text { Decitabine was found to induce } \mathrm{G}_{2} / \mathrm{M} \text { arrest, apoptosis, and } \\
\text { the expression of E-cadherin in EBVaGC cell line, SNU719 cells }\end{array}$ \\
\hline (64) & Schneider et al., 2017 & Phase I study & $\begin{array}{c}\text { Epigenetic priming with 5-azacytidine prior to chemotherapy } \\
\text { in patients with locally advanced esophageal/gastric } \\
\text { adenocarcinoma was well-tolerated with significant } \\
\text { clinical and epigenetic responses }\end{array}$ \\
\hline (65) & Liu et al., 2013 & $\begin{array}{l}\text { Experimental } \\
\text { research }\end{array}$ & $\begin{array}{l}\text { Gemcitabine and doxorubicin induced EBV lytic reactivation } \\
\text { through up-regulation of EBV immediate-early genes, } \\
\text { BZLF1 and BRLF1, in EBV-transformed B cells. }\end{array}$ \\
\hline
\end{tabular}

demonstrated that PX-866 (NCT00726583), BYL719 (NCT02551055), and MLN1117 (NCT01219699) showed antitumor activity in patients with incurable cancers including GC (41). Moreover, despite the absence of definitive beneficial effects of PI3K/AKT/mTOR pathway inhibitors, multiple clinical trials involving GC patients are still being carried out due to the possibility of targetable therapy in EBVaGC.

\section{Treatment for Epigenetic Abnormalities: Demethylating Agents}

Several studies demonstrated that epigenetic abnormalities, such as promoter hypermethylation, play a crucial role in the development and progression of EBVaGC (42-45). Methylation of both viral and host DNA is important in the carcinogenesis of EBVaGC. Particularly, these methylations control the expression of EBV lytic and latent genes.
EBVaGC is known to exhibit type I or II latency, in which EBV-encoded small RNAs (EBERs), EBV-determined nuclear antigen (EBNA) 1, BamHI A region rightward transcripts (BARTs), latent membrane protein (LMP) 2A, and BART miRNAs are all expressed (46). EBV lytic genes, including $B C L F 1, B H R F 1, B N L F 2 a$, and $B R L F 1$, are also expressed in EBVaGC (47). Ribeiro et al. revealed that the most frequently expressed EBV latent proteins are EBNA1 $(98.1 \%)$ and LMP2A (53.8\%), whereas LMP1 and LMP2B are only existed in $10 \%$ of cases. Lytic proteins, such as BARF0 and BARF1, and other lytic transcripts are present in approximately $50 \%$ of all cases (48). EBV LMP1 and 2A are known to activate cellular DNA methyltransferase which engages in the methylation of the viral and cellular genome (49). DNA methylation is a host defense mechanism against viral DNA to suppress the expression of viral genes, yet also plays an important role in allowing EBV to escape from the 
host immune system. The methylation of EBV DNA facilitates latency, which may contribute to the maintenance of EBVaGC.

Virus-induced methylation of the DNA of host cells inactivates tumor suppressor genes and tumor associated antigens (50). Global and non-random $\mathrm{CpG}$ island methylation in the promoter regions of many cancer-related genes, which down regulates their expression, is found in EBVaGC (51). The methylation frequencies of several tumorrelated genes and DNA loci have been demonstrated to be significantly higher in EBVaGC. EBVaGC also displays promotor hypermethylation in multiple genes related to cell cycle regulation (p14ARF, p15, p16INK4A, and p73), DNA repair (hMLH1, MGMT and GSTP1), cell adhesion and metastases (CDH1, TIMP1, and TIMP3), apoptosis (DAPK and bcl-2), and signal transduction (APC, PTEN, and RASSF1A) (52). Choi et al. reviewed published studies that reported DNA methylation in gastric cancers and found that 13 genes, p16 (CDKN2A), COX2, SSTR1, ACSS1, FAM3B, IHH, TRABD, SOX9, WNT5A, FSD1, IRF5, BCL7A, and PTEN, were hypermethylated in both primary EBVaGC and EBVaGC cell lines. Another 11 genes, ICAM1, TFF1, IL15RA, REC8, EPHB6, MDGA2, SCARF2, GKN1, GNN2, NEK9, and SLC7A8, were only hypermethylated in EBVaGC cell lines (53). The mechanism that activates cellular DNA methylation by EBV infection of the gastric epithelial cell is not clearly understood. Hino et al. reported that LMP2A can induce the transcription of DNA methyltransferase 1 (DNMT1) through STAT3 phosphorylations (54). However, LMP2A is not present in all cases of EBVaGC. LMP1 can also induce aberrant DNA methylation by activating DNMT1, yet LMP1 is scarcely expressed in EBVaGC (55). NambaFukuyo et al. suggested that downregulation of TET2 was important for promoting DNA methylation in EBVaGC. TET family genes encode DNA demethylase and TET2 is suppressed by EBV transcripts, such as BARF0 and LMP2A, and TET2-targeting miRNAs (56).

The important feature of epigenetic treatment is the reversibility of epigenetic gene alterations. The therapeutic application of DNA demethylating agents for EBVaGC may be attractive (Table III). Jung et al. reported that low concentrations of demethylating agents, 5-azacitidine or trichostatin A, induced the expression of EBV lytic genes, such as BMRF1, BZLF1, and BRLF1, in EBVaGC cell lines (57). As demethylating agents induce lytic EBV infection in latent EBV-infected cells, demethylating agents can induce the lysis of tumor cells $(58,59)$. Nakamura et al. reported that decitabine, a demethylating agent, modulated $\mathrm{G}_{2} / \mathrm{M}$ arrest, apoptosis, and the E-cadherin expression in SNU719 cells. The promoters of tumor-suppressor genes, such as p73 and Runt-related transcript factor 3 (RUNX3), were demethylated and their expression upregulated by decitabine treatment (60). Epigenetic agents have also shown antitumor activity against solid tumors in the case of single or combination treatment with standard chemotherapy. Schneider et al. carried out a phase I study of 5-azacytidine as a neoadjuvant chemotherapy in patients with locally advanced gastric and esophageal cancer. Epigenetic priming with 5-azacytidine prior to chemotherapy was well tolerated with significant epigenetic and clinical responses, thus a phase II study is underway using the established dose of 5azacitidine as a priming regimen (61). Liu et al. also reported that doxorubicin and gemcitabine activated EBV lytic reactivation through the overexpression of the EBV immediate early genes BZLF1 and BRLF1 in EBVtransformed B cells (62). Therefore, demethylating agents and EBV lytic phase inducing agents can be a useful therapeutic strategy for EBVaGC. However, further studies are needed to clarify the role of demethylating agents and EBV lytic phase inducing agents, along with combination approaches of these agents and standard treatment.

\section{Conclusion}

A more profound understanding of the underpinning tumor biology has recently opened a more contemporary clinical approach for AGC. EBVaGC is a distinct subtype of GC as regards both its molecular and clinicopathological features.

For EBVaGC, clinical studies have evaluated the role of molecular targeted agents using the characteristics of extreme DNA hypermethylation, recurrent PIK3CA mutations, and PD-L1/2 overexpression. As a result, the driving features of PD-L1 positivity or a high mutational burden can be targeted with immunotherapy as efficaciously as in a microsatellite-instable (MSI) subtype. Moreover, demethylating agents and EBV lytic phase inducing agents have also been shown to be useful therapeutic strategies for EBVaGC. However, further clinical studies are warranted to clarify the roles of these agents and the efficacy of a combination approach with standard treatment for AGC.

Since the identification of new biomarkers is essential for precision medicine, the unique molecular and clinical features of EBVaGC should be utilized to improve the prognosis for patients with this disease. Consequently, a better understanding of the molecular characteristics of EBVaGC and dedicated clinical trials will open new opportunities for personalized therapy.

\section{Conflicts of Interest}

The Authors declare that they have no conflicts of interest regarding this study.

\section{Authors' Contributions}

All Authors contributed to the conception and design of the study, as well as to drafting and revising the manuscript. 


\section{Acknowledgements}

This work was supported by a National Research Foundation of Korea (NRF) grant funded by the Korean Government (2014R1 A5A2009242).

\section{References}

1 Ferlay J, Colombet M, Soerjomataram I, Dyba T, Randi G, Bettio M, Gavin A, Visser O and Bray F: Cancer incidence and mortality patterns in Europe: Estimates for 40 countries and 25 major cancers in 2018. Eur J Cancer 103: 356-387, 2018. PMID: 30100160. DOI: 10.1016/j.ejca.2018.07.005

2 Jung KW, Won YJ, Kong HJ and Lee ES: Prediction of cancer incidence and mortality in Korea, 2018. Cancer Res Treat 50: 317-323, 2018. PMID: 29566480. DOI: 10.4143/crt.2018.142

3 Bang YJ, Van Cutsem E, Feyereislova A, Chung HC, Shen L, Sawaki A, Lordick F, Ohtsu A, Omuro Y, Satoh T, Aprile G, Kulikov E, Hill J, Lehle M, Ruschoff J and Kang YK; ToGA Trial Investigators: Trastuzumab in combination with chemotherapy versus chemotherapy alone for treatment of HER2-positive advanced gastric or gastro-oesophageal junction cancer (ToGA): a phase 3, open-label, randomised controlled trial. Lancet 376: 687-697, 2010. PMID: 20728210. DOI: 10.1016/S0140-6736(10)61121-X

4 Wilke H, Muro K, Van Cutsem E, Oh SC, Bodoky G, Shimada Y, Hironaka S, Sugimoto N, Lipatov O, Kim TY, Cunningham D, Rougier P, Komatsu Y, Ajani J, Emig M, Carlesi R, Ferry D, Chandrawansa K, Schwartz JD, Ohtsu A and Group RS: Ramucirumab plus paclitaxel versus placebo plus paclitaxel in patients with previously treated advanced gastric or gastrooesophageal junction adenocarcinoma (RAINBOW): a doubleblind, randomised phase 3 trial. Lancet Oncol 15: 1224-1235, 2014. PMID: 25240821. DOI: 10.1016/S1470-2045(14)70420-6

5 Kang YK, Boku N, Satoh T, Ryu MH, Chao Y, Kato K, Chung HC, Chen JS, Muro K, Kang WK, Yeh KH, Yoshikawa T, Oh SC, Bai LY, Tamura T, Lee KW, Hamamoto Y, Kim JG, Chin K, Oh DY, Minashi K, Cho JY, Tsuda M and Chen LT: Nivolumab in patients with advanced gastric or gastro-oesophageal junction cancer refractory to, or intolerant of, at least two previous chemotherapy regimens (ONO-4538-12, ATTRACTION-2): a randomised, double-blind, placebo-controlled, phase 3 trial. Lancet 390: 2461-2471, 2017. PMID: 28993052. DOI: 10.1016/S0140-6736(17)31827-5

6 Digklia A and Wagner AD: Advanced gastric cancer: Current treatment landscape and future perspectives. World $\mathrm{J}$ Gastroenterol 22: 2403-2414, 2016. PMID: 26937129. DOI: 10.3748/wjg.v22.i8.2403

7 Cancer Genome Atlas Research Network: Comprehensive molecular characterization of gastric adenocarcinoma. Nature 513: 202-209, 2014. PMID: 25079317. DOI: 10.1038/ nature13480

8 Naseem M, Barzi A, Brezden-Masley C, Puccini A, Berger MD, Tokunaga R, Battaglin F, Soni S, McSkane M, Zhang W and Lenz HJ: Outlooks on Epstein-Barr virus associated gastric cancer. Cancer Treat Rev 66: 15-22, 2018. PMID: 29631196. DOI: $10.1016 /$ j.ctrv.2018.03.006

9 Nishikawa J, Iizasa H, Yoshiyama H, Shimokuri K, Kobayashi Y, Sasaki S, Nakamura M, Yanai H, Sakai K, Suehiro Y, Yamasaki $\mathrm{T}$ and Sakaida I: Clinical importance of Epstein-Barr virusassociated gastric cancer. Cancers 10, 2018. PMID: 29843478.
DOI: $10.3390 /$ cancers 10060167

10 Kim SY, Park C, Kim HJ, Park J, Hwang J, Kim JI, Choi MG, Kim S, Kim KM and Kang MS: Deregulation of immune response genes in patients with Epstein-Barr virus-associated gastric cancer and outcomes. Gastroenterology 148: 137-147, 2015. PMID: 25254613. DOI: 10.1053/j.gastro.2014.09.020

11 Kang BW, Seo AN, Yoon S, Bae HI, Jeon SW, Kwon OK, Chung HY, Yu W, Kang H and Kim JG: Prognostic value of tumor-infiltrating lymphocytes in Epstein-Barr virus-associated gastric cancer. Ann Oncol 27: 494-501, 2016. PMID: 26673353. DOI: $10.1093 /$ annonc/mdv610

12 Seo AN, Kang BW, Kwon OK, Park KB, Lee SS, Chung HY, Yu W, Bae HI, Jeon SW, Kang H and Kim JG: Intratumoural PDL1 expression is associated with worse survival of patients with Epstein-Barr virus-associated gastric cancer. Brit J Cancer 117: 1753-1760, 2017. PMID: 29073638. DOI: 10.1038/bjc.2017.369

13 Davidson $\mathrm{M}$ and Chau I: Immunotherapy for oesophagogastric cancer. Expert Opin Biol Ther 16: 1197-1207, 2016. PMID: 27409159. DOI: $10.1080 / 14712598.2016 .1213233$

14 Fashoyin-Aje L, Donoghue M, Chen HY, He K, Veeraraghavan J, Goldberg KB, Keegan P, McKee AE and Pazdur R: FDA approval summary: Pembrolizumab for recurrent locally advanced or metastatic gastric or gastroesophageal junction adenocarcinoma expressing PD-L1. Oncologist 24: 103-109, 2019. PMID: 30120163. DOI: 10.1634/theoncologist.2018-0221

15 Fuchs CS, Doi T, Jang RW, Muro K, Satoh T, Machado M, Sun WJ, Jalal SI, Shah MA, Metges JP, Garrido M, Golan T, Mandala M, Wainberg ZA, Catenacci DV, Ohtsu A, Shitara K, Geva R, Bleeker J, Ko AH, Ku G, Philip P, Enzinger PC, Bang YJ, Levitan D, Wang JD, Rosales M, Dalal RP and Yoon HH: Safety and efficacy of pembrolizumab monotherapy in patients with previously treated advanced gastric and gastroesophageal junction cancer phase 2 Clinical KEYNOTE-059 trial. JAMA Oncol 4, 2018. PMID: 29543932. DOI: 10.1001/jamaoncol. 2018.0013

16 Bang YJ, Ruiz EY, Van Cutsem E, Lee KW, Wyrwicz L, Schenker M, Alsina M, Ryu MH, Chung HC, Evesque L, AlBatran SE, Park SH, Lichinitser M, Boku N, Moehler MH, Hong J, Xiong H, Hallwachs R, Conti I and Taieb J: Phase III, randomised trial of avelumab versus physician's choice of chemotherapy as third-line treatment of patients with advanced gastric or gastro-oesophageal junction cancer: primary analysis of JAVELIN Gastric 300. Ann Oncol 29: 2052-2060, 2018. PMID: 30052729. DOI: 10.1093/annonc/mdy264

17 Lin EM, Gong J, Klempner SJ and Chao J: Advances in immuno-oncology biomarkers for gastroesophageal cancer: programmed death ligand 1 , microsatellite instability, and beyond. World J Gastroenterol 24: 2686-2697, 2018. PMID: 29991874. DOI: $10.3748 /$ wjg.v24.i25.2686

18 Vrana D, Matzenauer M, Neoral C, Aujesky R, Vrba R, Melichar B, Rusarova N, Bartouskova M and Jankowski J: From tumor immunology to immunotherapy in gastric and esophageal cancer. Int J Mol Sci 20, 2018. PMID: 30577521. DOI: 10.3390/ijms 20010013

19 Kim ST, Cristescu R, Bass AJ, Kim KM, Odegaard JI, Kim K, Liu XQ, Sher X, Jung H, Lee M, Lee S, Park SH, Park JO, Park YS, Lim HY, Lee H, Choi M, Talasaz A, Kang PS, Cheng J, Loboda A, Lee $\mathrm{J}$ and Kang WK: Comprehensive molecular characterization of clinical responses to PD-1 inhibition in metastatic gastric cancer. Nat Med 24: 1449-1458, 2018. PMID: 30013197. DOI: 10.1038/s41591-018-0101-Z 
20 Zhang M, Dong Y, Liu H, Wang Y, Zhao S, Xuan Q, Wang Y and Zhang Q: The clinicopathological and prognostic significance of PD-L1 expression in gastric cancer: a metaanalysis of 10 studies with 1,901 patients. Sci Rep 6: 37933 2016. PMID: 27892511. DOI: 10.1038/srep37933

21 Darvin P, Toor SM, Sasidharan Nair V and Elkord E: Immune checkpoint inhibitors: recent progress and potential biomarkers. Exp Mol Med 50: 165, 2018. PMID: 30546008. DOI: 10.1038/s12276-018-0191-1

22 Kankeu Fonkoua L and Yee NS: Molecular characterization of gastric carcinoma: Therapeutic implications for biomarkers and targets. Biomedicines 6, 2018. PMID: 29522457. DOI: 10.3390/biomedicines6010032

23 Cristescu R, Lee J, Nebozhyn M, Kim KM, Ting JC, Wong SS, Liu J, Yue YG, Wang J, Yu K, Ye XS, Do IG, Liu S, Gong L, Fu J, Jin JG, Choi MG, Sohn TS, Lee JH, Bae JM, Kim ST, Park SH, Sohn I, Jung SH, Tan P, Chen R, Hardwick J, Kang WK, Ayers M, Hongyue D, Reinhard C, Loboda A, Kim S and Aggarwal A: Molecular analysis of gastric cancer identifies subtypes associated with distinct clinical outcomes. Nat Med 21: 449-456, 2015. PMID: 25894828. DOI: 10.1038/nm.3850

24 Tzenaki N and Papakonstanti EA: p110delta PI3 kinase pathway: emerging roles in cancer. Front Oncol 3: 40, 2013. PMID: 23459844. DOI: $10.3389 /$ fonc 2013.00040

25 Wang W, Lv J, Wang L, Wang X and Ye L: The impact of heterogeneity in phosphoinositide 3-kinase pathway in human cancer and possible therapeutic treatments. Semin Cell Dev Biol 64: 116-124, 2017. PMID: 27582428. DOI: 10.1016/j.semcdb. 2016.08.024

26 Samuels Y and Ericson K: Oncogenic PI3K and its role in cancer. Curr Opin Oncol 18: 77-82, 2006. PMID: 16357568. DOI: 10.1097/01.cco.0000198021.99347.b9

27 Abe H, Kaneda A and Fukayama M: Epstein-Barr virusassociated gastric carcinoma: Use of host cell machineries and somatic gene mutations. Pathobiology 82: 212-223, 2015. PMID: 26337667. DOI: 10.1159/000434683

28 Janku F, Yap TA and Meric-Bernstam F: Targeting the PI3K pathway in cancer: are we making headway? Nat Rev Clin Oncol 15: 273-291, 2018. PMID: 29508857. DOI: 10.1038/ nrclinonc. 2018.28

29 Fruman DA, Chiu H, Hopkins BD, Bagrodia S, Cantley LC and Abraham RT: The PI3K pathway in human disease. Cell 170: 605635, 2017. PMID: 28802037. DOI: 10.1016/j.cell. 2017.07.029

30 Janku F: Phosphoinositide 3-kinase (PI3K) pathway inhibitors in solid tumors: From laboratory to patients. Cancer Treat Rev 59: 93-101, 2017. PMID: 28779636. DOI: 10.1016/j.ctrv.2017. 07.005

31 Samuels Y, Wang Z, Bardelli A, Silliman N, Ptak J, Szabo S, Yan H, Gazdar A, Powell SM, Riggins GJ, Willson JK, Markowitz S, Kinzler KW, Vogelstein B and Velculescu VE: High frequency of mutations of the PIK3CA gene in human cancers. Science 304: 554, 2004. PMID: 15016963. DOI: 10.1126/science. 1096502

32 Wadhwa R, Song S, Lee JS, Yao Y, Wei Q and Ajani JA: Gastric cancer-molecular and clinical dimensions. Nat Rev Clin Oncol 10: 643-655, 2013. PMID: 24061039. DOI: 10.1038/ nrclinonc.2013.170

33 Markman B, Dienstmann R and Tabernero J: Targeting the $\mathrm{PI} 3 \mathrm{~K} / \mathrm{Akt} / \mathrm{mTOR}$ pathway--beyond rapalogs. Oncotarget 1: 530543, 2010. PMID: 21317449. DOI: 10.18632/oncotarget.101012
34 Diaz-Serrano A, Angulo B, Dominguez C, Pazo-Cid R, Salud A, Jimenez-Fonseca P, Leon A, Galan MC, Alsina M, Rivera F, Plaza JC, Paz-Ares L, Lopez-Rios F and Gomez-Martin C: Genomic profiling of HER2-positive gastric cancer: $\mathrm{PI} 3 \mathrm{~K} / \mathrm{Akt} / \mathrm{mTOR}$ pathway as predictor of outcomes in HER2positive advanced gastric cancer treated with trastuzumab. Oncologist 23: 1092-1102, 2018. PMID: 29700210. DOI: 10.1634/theoncologist.2017-0379

35 Fang WL, Huang KH, Lan YT, Lin CH, Chang SC, Chen MH, Chao Y, Lin WC, Lo SS, Li AF, Wu CW, Chiou SH and Shyr YM: Mutations in PI3K/AKT pathway genes and amplifications of PIK3CA are associated with patterns of recurrence in gastric cancers. Oncotarget 7: 6201-6220, 2016. PMID: 26701847. DOI: 10.18632/oncotarget.6641

36 Ito C, Nishizuka SS, Ishida K, Uesugi N, Sugai T, Tamura G, Koeda K and Sasaki A: Analysis of PIK3CA mutations and PI3K pathway proteins in advanced gastric cancer. J Surg Res 212: 195204, 2017. PMID: 28550907. DOI: 10.1016/j.jss.2017. 01.018

37 Ramanathan RK, McDonough SL, Kennecke HF, Iqbal S, Baranda JC, Seery TE, Lim HJ, Hezel AF, Vaccaro GM and Blanke CD: Phase 2 study of MK-2206, an allosteric inhibitor of AKT, as second-line therapy for advanced gastric and gastroesophageal junction cancer: A SWOG cooperative group trial (S1005). Cancer-Am Cancer Soc 121: 2193-2197, 2015. PMID: 25827820. DOI: 10.1002/cncr.29363

38 Farran B, Muller S and Montenegro RC: Gastric cancer management: Kinases as a target therapy. Clin Exp Pharmacol Physiol 44: 613-622, 2017. PMID: 28271563. DOI: 10.1111/ 1440-1681.12743

39 Ang YL, Yong WP and Tan P: Translating gastric cancer genomics into targeted therapies. Crit Rev Oncol Hematol 100: 141-146, 2016. PMID: 26947813. DOI: 10.1016/j.critrevonc. 2016.02.007

40 Ohtsu A, Ajani JA, Bai YX, Bang YJ, Chung HC, Pan HM, Sahmoud T, Shen L, Yeh KH, Chin K, Muro K, Kim YH, Ferry D, Tebbutt NC, Al-Batran SE, Smith H, Costantini C, Rizvi S, Lebwohl D and Van Cutsem E: Everolimus for previously treated advanced gastric cancer: results of the randomized, double-blind, phase III GRANITE-1 study. J Clin Oncol 31: 3935-3943, 2013. PMID: 24043745. DOI: 10.1200/JCO.2012. 48.3552

41 Hong DS, Bowles DW, Falchook GS, Messersmith WA, George GC, O'Bryant CL, Vo AC, Klucher K, Herbst RS, Eckhardt SG, Peterson S, Hausman DF, Kurzrock $\mathrm{R}$ and Jimeno A: A multicenter phase I trial of PX-866, an oral irreversible phosphatidylinositol 3-kinase inhibitor, in patients with advanced solid tumors. Clin Cancer Res 18: 4173-4182, 2012. PMID: 22693357. DOI: 10.1158/1078-0432.CCR-12-0714

42 Feinberg AP: The epigenetics of cancer etiology. Semin Cancer Biol 14: 427-432, 2004. PMID: 15489135. DOI: 10.1016/ j.semcancer.2004.06.005

43 Zhao JH, Liang QY, Cheung KF, Kang W, Lung RWM, Tong JHM, To KF, Sung JJY and Yu J: Genome-wide identification of Epstein-Barr virus-driven promoter methylation profiles of human genes in gastric cancer cells. Cancer 119: 304-312, 2013. PMID: 22833454. DOI: $10.1002 / \mathrm{cncr} .27724$

44 Kaneda A, Matsusaka K, Aburatani H and Fukayama M: Epstein-Barr virus infection as an epigenetic driver of tumorigenesis. Cancer Res 72: 3445-3450, 2012. PMID: 22761333. DOI: 10.1158/0008-5472.Can-11-3919 
45 Saito S, Murata T, Kanda T, Isomura H, Narita Y, Sugimoto A, Kawashima D and Tsurumi T: Epstein-Barr virus deubiquitinase downregulates TRAF6-mediated NF-kappa B signaling during productive replication. J Virol 87: 4060-4070, 2013. PMID: 23365429. DOI: $10.1128 /$ Jvi.02020-12

46 Shinozaki-Ushiku A, Kunita A and Fukayama M: Update on Epstein-Barr virus and gastric cancer. Int J Oncol 46: 1421-1434, 2015. PMID: 25633561. DOI: 10.3892/ijo.2015.2856

47 Strong MJ, Laskow T, Nakhoul H, Blanchard E, Liu YZ, Wang $\mathrm{X}$, Baddoo $\mathrm{M}$, Lin Z, Yin QY and Flemington EK: Latent expression of the Epstein-Barr virus (EBV)-encoded major histocompatibility complex class I TAP inhibitor, BNLF2a, in EBV-positive gastric carcinomas. J Virol 89: 10110-10114, 2015. PMID: 26178981. DOI: 10.1128/Jvi.01110-15

48 Ribeiro J, Oliveira C, Malta M and Sousa H: Epstein-Barr virus gene expression and latency pattern in gastric carcinomas: a systematic review. Future Oncol 13: 567-579, 2017. PMID: 28118740. DOI: $10.2217 /$ fon-2016-0475

49 Niller HH, Banati F, Salamon D and Minarovits J: Epigenetic alterations in Epstein-Barr virus-associated diseases. Adv Exp Med Biol 879: 39-69, 2016. PMID: 26659263. DOI: 10.1007/ 978-3-319-24738-0_3

50 Kang GH, Lee S, Kim WH, Lee HW, Kim JC, Rhyu MG and Ro JY: Epstein-Barr virus-positive gastric carcinoma demonstrates frequent aberrant methylation of multiple genes and constitutes $\mathrm{CpG}$ island methylator phenotype-positive gastric carcinoma. Am J Pathol 160: 787-794, 2002. PMID: 11891177. DOI: Doi 10.1016/S0002-9440(10)64901-2

51 Chen JN, He D, Tang F and Shao CK: Epstein-Barr virusassociated gastric carcinoma a newly defined entity. J Clin Gastroenterol 46: 262-271, 2012. PMID: 22392024. DOI: 10.1097/MCG.0b013e318249c4b8

52 Chapel F, Fabiani B, Davi F, Raphael M, Tepper M, Champault $\mathrm{G}$ and Guettier C: Epstein-Barr virus and gastric carcinoma in western patients: comparison of pathological parameters and p53 expression in EBV-positive and negative tumours. Histopathology 36: 252-261, 2000. PMID: 10692029. DOI: doi.org/10.1046/j.1365-2559.2000.00843.x

53 Choi SJ, Shin YS, Kang BW, Kim JG, Won KJ, Lieberman PM, Cho $\mathrm{H}$ and Kang H: DNA hypermethylation induced by EpsteinBarr virus in the development of Epstein-Barr virus-associated gastric carcinoma. Arch Pharm Res 40: 894-905, 2017. PMID: 28779374. DOI: 10.1007/s12272-017-0939-5

54 Hino R, Uozaki H, Murakami N, Ushiku T, Shinozaki A, Ishikawa S, Morikawa T, Nakaya T, Sakatani T, Takada $\mathrm{K}$ and Fukayama M: Activation of DNA methyltransferase 1 by EBV Latent Membrane Protein 2A leads to promoter hypermethylation of PTEN gene in gastric carcinoma. Cancer Res 69: 2766-2774, 2009. PMID: 19339266. DOI: 10.1158/ 0008-5472.Can-08-3070

55 Kida Y, Miyauchi K and Takano Y: Gastric adenocarcinoma with differentiation to sarcomatous components associated with monoclonal Epstein-Barr-virus infection and Lmp-1 expression. Virchows Arch A 423: 383-387, 1993. PMID: 8116227.
56 Namba-Fukuyo H, Funata S, Matsusaka K, Fukuyo M, Rahmutulla B, Mano Y, Fukayama M, Aburatani H and Kaneda A: TET2 functions as a resistance factor against DNA methylation acquisition during Epstein-Barr virus infection. Oncotarget 7: 81512-81526, 2016. PMID: 27829228. DOI: 10.18632 /oncotarget.13130

57 Jung EJ, Lee YM, Lee BL, Chang MS and Kim WH: Lytic induction and apoptosis of Epstein-Barr virus-associated gastric cancer cell line with epigenetic modifiers and ganciclovir. Cancer Lett 247: 77-83, 2007. PMID: 16647201. DOI: 10.1016/j.canlet.2006.03.022

58 Chang MS, Uozaki H, Chong JM, Ushiku T, Sakuma K, Ishikawa S, Hino R, Barua RR, Iwasaki Y, Arai K, Fujii H, Nagai $\mathrm{H}$ and Fukayama M: $\mathrm{CpG}$ island methylation status in gastric carcinoma with and without infection of Epstein-Barr virus. Clin Cancer Res 12: 2995-3002, 2006. PMID: 16707594. DOI: $10.1158 / 1078-0432$.Ccr-05-1601

59 Kusano M, Toyota M, Suzuki H, Akino K, Aoki F, Fujita M, Hosokawa M, Shinomura Y, Imai K and Tokino T: Genetic, epigenetic, and clinicopathologic features of gastric carcinomas with the $\mathrm{CpG}$ island methylator phenotype and an association with Epstein-Barr virus. Cancer 106: 1467-1479, 2006. PMID: 16518809. DOI: $10.1002 / \mathrm{cncr} .21789$

60 Nakamura M, Nishikawa J, Saito M, Sakai K, Sasaki S, Hashimoto S, Okamoto T, Suehiro Y, Yamasaki T and Sakaida I: Decitabine inhibits tumor cell proliferation and up-regulates E-cadherin expression in Epstein-Barr virus-associated gastric cancer. J Med Virol 89: 508-517, 2017. PMID: 27430892. DOI: 10.1002/jmv. 24634

61 Schneider BJ, Shah MA, Klute K, Ocean A, Popa E, Altorki N, Lieberman M, Schreiner A, Yantiss R, Christos PJ, Palmer R, You DQ, Viale A, Kermani P and Scandura JM: Phase I study of epigenetic priming with azacitidine prior to standard neoadjuvant chemotherapy for patients with resectable gastric and esophageal adenocarcinoma: Evidence of tumor hypomethylation as an indicator of major histopathologic response. Clin Cancer Res 23: 2673-2680, 2017. PMID: 27836862. DOI: 10.1158/10780432.Ccr-16-1896

62 Liu X, Wang Y, Wang XF, Sun ZF, Li LL, Tao Q and Luo B: Epigenetic silencing of WNT5A in Epstein-Barr virus-associated gastric carcinoma. Arch Virol 158: 123-132, 2013. PMID: 23001722. DOI: $10.1007 / \mathrm{s} 00705-012-1481-x$
Received June 28, 2019

Revised July 3, 2019

Accepted July 4, 2019 